Denning examines the dates of abundant showers of Perseids and finds that a large proportion of them can be satisfied by a period of II 75 years. This period would give an abundant shower for the year I 592, and Mr. Denning has included that year, apparently on Mr. Beveridge's authority, in the list of years of observed maxima. A list of Perseid showers, or at least of showers at the time of year when Perseids are expected, is to be found in Arago, "Astronomie populaire," iv. p. 296-8, and is extracted from Biot's "Catalogue général des étoiles filantes . . observés en Chine," published in Mémoives présentés à l'Academie, sciences math. et phys., x., p. I29, etc. To these Chinese observations it is possible to add one from Matthew Paris of the date 1243 July 26. The complete series then becomes: 7 I 4 July I5, 784 July Io, 830 July 22,833 July 23,835 July 22 , $84 \mathrm{I}$ July 2I, 865 Aug. I, 924 July 2 I-23, 925 July 22, 23, 926 July 22, 933 July 20-25, 1243 July 26, I45 I July 27 , all Julian dates.

An analysis of the dates of the medieval observations shows that the date of maximum intensity of the Perseid shower has not shifted its position in the sidereal year since the year 830 at latest. The date corresponds to a solar longitude of $138^{\circ}$ reduced to the equinox of 1900 . A few of the showers recorded in history fall a little before or after that date, and in two instances ( 784 and 865$)$ the difference is as much as ten days on either side of the normal maximum. In $\mathrm{I} 592$, on the other hand, the recorded shower falls nineteen days earlier than the normal maximum, and this raises a doubt whether it was really a Perseid shower at all or some otherwise unknown shower which happened to fall in a year when an abundant Perseid shower was due. J. K. Fotheringham.

University Observatory, Oxford, May 2 I.

\section{The Measurement of Overvoltage.}

In general, the term overvoltage refers to the difference between the potential required to discharge an ion at a particular electrode and the calculated reversible value, in the same electrolyte. Strictly speaking, therefore, overvoltage only exists while the current is flowing, and hence measurements should be made under these conditions. Some workers, however, state that the " transfer resistance" of a gas film at the electrode causes the measured potential to be in excess of the true value; consequently, an alternative method has been adopted in which a rotating commutator rapidly interrupts the polarising current and connects the experimental electrode with the potentiometer system. In this way disturbing influences due to transfer resistance are said to be eliminated, since the potential of the electrode is measured when the current is not flowing. This method gives lower results than the direct method for the following reasons: (I) When the polarising circuit is broken, an extremely rapid fall of potential occurs, which is appreciable even in the small interval that elapses between the periods when current flows; (2) since the current only flows intermittently through the experimental cell, current density and time effects are not comparable with those obtained when the current flows continuously; (3) the continual make and break of the circuit by the commutator sets up alternating induced currents, and it is well known that electrical discharges of such a nature tend to lower the potential of a polarised electrode.

In some recent work, hitherto unpublished, the magnitude of the effects due to these induced currents has been investigated. The lowering of potential was found to depend upon the particular electrode examined, and was usually of the order of 0.3 volt, and in some cases as much as 0.5 volt. The value of the induced current, and consequently its effect on the potential, will depend on the frequency of the intermittent current, and upon the resistance and self-inductance of the circuit; but it seems fairly certain that the lowering of potential, due to induced currents in the commutator method for measuring overvoltage, is considerable.

In order to eliminate as many sources of error as possible, the following method for the measurement of overvoltage is being tested. The commutator method is being used, but a " choking coil " of high self-inductance is placed in the circuit in order to reduce the induced current to a negligible amount. Further, instead of the polarising and potentiometer circuits being made for equal intervals of time, the latter will only be complete for about $\mathrm{IO}^{\circ}$ in each revolution. Thus for about 97 per cent. of the time the polarising current will flow through the cell, and, if the commutator revolves 3000 times per minute, only 0.0007 seconds will elapse between opening and closing the current circuit. To ascertain the magnitude of the fall of potential during this period, further experiments will be made, either by varying the speed of the commutator, or by increasing the period per revolution in which the experimental electrode is connected with the potentiometer system. By extrapolation, it should be possible to determine the potential of the electrode at the instant of breaking the current, and the results compared with those obtained while current is still flowing, in order to determine the effect of the so-called "transfer resistance." S. Glasstone.

University College, Exeter, May 22.

\section{A New Phototropic Compound of Mercury.}

IN an attempt to prepare the phototropic compound, dimercuric-diiodo-disulphide, described by Dr. Ray (Jour. Chem. Soc. I9I7, T, IoI-I09), we accidentally discovered a new phototropic mercury compound of the formula $\mathrm{Hg}{ }_{\mathrm{CNS}}^{\mathrm{HS}}$ through a mistake of the laboratory attendant in supplying us with potassium nitrate in the place of the nitrite. The compound is prepared by the interaction of a mercuric salt with ammonium sulphocyanide and thio-urea in a solution of acetic acid in the presence of an oxidising agent. The compound is also prepared by the action of hydrogen sulphide on mercuric sulphocyanide. This gives us a clue to the constitution of the yellow mercuric compound.

The compound is very phototropic, inasmuch as it is effected by strong sunlight in less than $1 / 6$ oth of a second and by diffused daylight in a few seconds. It appears, therefore, to be the most phototropic compound as yet known. In researches on this compound we have prepared a red variety of mercuric sulphide by precipitation methods. Again, by the decomposition of the yellow mercuric compound, we have prepared a yellow variety of mercuric sulphide which shows interesting thermotropic properties. By the action of free iodine on the new phototropic compound, an iodine compound of mercury which is also phototropic has been prepared. . Further work is in progress.

Y. VENKATARAMAIAH. Bh. S. V. Raghava Rao.

Research Laboratories, Maharaja's College, Vizianagram, May 9.

NO. 2797 , VOL. III] 